\title{
(a) OPEN ACCESS \\ Changes in health and social well-being in the COVID-19 clinically vulnerable older English population during the pandemic
}

\author{
Giorgio Di Gessa $\odot,{ }^{1}$ Debora Price ${ }^{2}$
}

\begin{abstract}
- Additional supplemental material is published online only. To view, please visit the journal online (http://dx. doi.org/10.1136/jech-2021216405)
\end{abstract}

${ }^{1}$ Department of Epidemiology and Public Health, University College London, London, UK 2Department of Sociology, Manchester Institute for Collaborative Research on Ageing, The University of Manchester, Manchester, UK

\section{Correspondence to} Dr Giorgio Di Gessa, Department of Epidemiology and Public Health, University College London, London WC1E 7HB, UK; g.di-gessa@ucl.ac.uk

Received 5 January 2021 Revised 25 February 2021 Accepted 8 April 2021 Published Online First 4 May 2021

\section{Check for updates}

(C) Author(s) (or their employer(s)) 2021. Re-use permitted under CC BY-NC. No commercial re-use. See rights and permissions. Published by BMJ.

To cite: Di Gessa G, Price D. Epidemiol Community Health 2021;75:1070-1077.

\begin{abstract}
Background People with specific health profiles and diseases (such as diabetes, lung and heart conditions) have been classified as 'clinically vulnerable' (CV) to COVID-19, that is, at higher risk of severe illness and mortality from COVID-19, and were targeted for shielding. However, there is as yet little evidence on how the pandemic and shielding impacted the health and social well-being of CV older people.
\end{abstract}

Methods We used data from wave 9 (2018/2019) and the first COVID-19 substudy (June/July 2020) of the English Longitudinal Study of Ageing. Using logistic and linear regression models, we investigated associations between being $\mathrm{CV}$ and health and social well-being during the pandemic, while controlling for prepandemic levels of the outcome variables. We also explored the interactions between CV and age group (50s, 60s, 70s, 80+), and between CV and shielding.

Results CV people were more likely to report worse health and social well-being outcomes during the pandemic, even taking into account prepandemic differences. However, changes in health were not uniform across different age groups, and CV respondents were generally at greater risks of deterioration in health and social well-being compared with those not CV in the same age group. CV respondents who were shielding reported worse outcomes compared with those not CV and not shielding.

Conclusions While policies focusing on shielding CV older people reduce rates of hospitalisation and death from COVID-19, policymakers should also pay attention to understanding and addressing the wider needs of this group if their long-term health and social well-being are not to be compromised.

\section{INTRODUCTION}

Within a short time of the COVID-19 epidemic's beginnings in Wuhan, China, clinical data revealed that the risk of severity of illness and death increased exponentially with age, and that a range of pre-existing health problems and chronic diseases all also correlated with age, predicted poor outcomes and mortality. ${ }^{1-3}$ Multivariate analysis soon suggested that age, health and disease independently predicted severity of illness and mortality from COVID-19. ${ }^{4-6}$ This led rapidly to the characterisation of populations who might be targeted for 'shielding' policies ranging from guidance to restrictions of movement. ${ }^{7}$ In England, strict lockdown and orders to stay at home were announced by the UK Government on 23 March 2020. In particular, high-risk individuals (ie, clinically extremely vulnerable) were advised to 'shield', that is, not leave their homes, and within their homes to minimise all non-essential contact with other members of their household. This group at high risk included people who have had an organ transplant, those who are having treatments that can affect the immune system and those with serious heart or lung conditions. Similarly, all people over 70 and those with identified underlying health conditions (such as diabetes, asthma or hepatitis) were classified as 'clinically vulnerable' (CV; at moderate risk) and were also advised to stay indoors and limit their interactions with other people outside the household. Although these rules were somewhat relaxed in June, many restrictions remained in place, with vulnerable people advised to stay at home as much as possible and to take particular care to minimise contact with others outside their household. ${ }^{8-11}$

Over the last few months, several studies have investigated mental health and health behaviours before and during the COVID-19 pandemic using representative samples and measuring changes either within individuals, across the population as a whole or across specific subgroups. ${ }^{12-18}$ Results suggest that health deteriorated particularly among younger age groups, whereas older adults seem to have fared better during the pandemic. Yet, in these studies, older people have been portrayed and considered as a homogeneously vulnerable group, with analyses grouping together all people aged 55, 65 or 70 years and older and failing to acknowledge that older people are a diverse group. A recent report ${ }^{19}$ which used the English Longitudinal Study of Ageing (ELSA) and focused specifically on older people suggests that those instructed by the National Health Service (NHS) or their general practitioner (GP) to shield were more likely to report poorer mental health and lower quality of life (QoL; even when prepandemic health measures were taken into account) as well as unhealthy behaviours during the pandemic compared with the remainder. Similar results were reported also among older individuals with multiple long-term health conditions. ${ }^{20}$ Both reports provide an important contribution to the understanding of older people's health during the initial lockdown and of the effect of social isolation and underlying health conditions. However, they are descriptive in nature and did not take into account important socioeconomic and demographic characteristics such as wealth, education and ethnicity, which are 
well known to be associated with both chronic conditions and health in later life. Moreover, to date, no studies have attempted to disentangle the subtleties and interaction of clinical vulnerability with old age, failing to acknowledge that risks to health and social well-being during the pandemic are not homogeneously distributed among 'older people'.

Older people with underlying health conditions, even prepandemic, faced challenges in terms of access to healthcare services and social contact and experienced more emotional distress, higher risk of loneliness and poorer QoL than non-vulnerable individuals. ${ }^{21-24}$ During the pandemic, these issues might have been exacerbated by the guidance to stay at home and minimise social contacts as well as by reduced care provision. Moreover, although UK guidelines considered all people who are aged 70 and above as being $\mathrm{CV}$, people in this age group with no underlying health conditions might regard themselves as fit and healthy and might have acted differently during the pandemic (keeping social interactions while maintaining physical distancing, or leaving the home even for limited purposes for instance). Thus, it is likely that not all $70+$ older people had similar experiences during the pandemic and that, in this wide age group, it was those with clinical vulnerabilities who experienced poorer health and social well-being.

Therefore, in this paper we aim to further our understanding of how the pandemic and shielding impacted the health and social well-being in the over-50 population classified as 'clinically vulnerable' to COVID-19. In particular, we aim to answer two research questions: first, were 'clinically vulnerable' older people more likely to be disproportionately disadvantaged in terms of their health and social well-being during the pandemic, and was this impact similar across different age groups? Second, as CV people are more likely to shield, is there a multiplicative effect of shielding and clinical vulnerabilities on health and social well-being in later life? We use data from the ELSA to answer these research questions, taking into consideration a number of health and social well-being measures which reflect people's health and have been associated with precarity in later life, ageing well and mortality. ${ }^{25-30}$

As the UK and other countries move into phases of intermittent lockdowns, CV and older people remain an important population category to be prioritised for stay-at-home advice. Identifying the groups most at risk of detrimental health and social well-being changes and understanding the impact of shielding in the CV population might help local authorities and agencies to target those needing additional support.

\section{METHODS}

\section{Study population}

We used the most recent prepandemic data (wave 9, collected in 2018/2019) and the first wave of the COVID-19 substudy (collected in June/July 2020) of the ELSA. ${ }^{31}$ ELSA is a longitudinal biennial survey of individuals aged 50 and over in private households. During the pandemic, 9392 ELSA members were invited to participate online or by computer-assisted telephone interviewing to the COVID-19 substudy (75\% response rate). Longitudinal analyses were based on core respondents interviewed during the COVID-19 crisis with available information in wave $9(n=5585)$. Further details of the survey's sampling frame and methodology can be found at https://www.elsa-project.ac. $\mathrm{uk} /$. Informed consent was obtained from all participants. All data are available through the UK Data Service (SN 8688 and 5050).

\section{Main measurement of interest}

\section{Clinical vulnerability to COVID-19}

Our key independent variable was a binary indicator which distinguished respondents by whether they were at higher risk of poor outcomes with coronavirus, that is, CV to COVID-19 (which we term 'CV' in the remainder of this paper), or not. Matching ELSA data as closely as possible to the definition of clinical vulnerability initially set out by the NHS in the UK, ${ }^{11}$ a respondent was classified as CV if in wave 9 (or since wave 9) they reported that a doctor had told them that they have a chronic lung disease, asthma, coronary heart disease, Parkinson's disease, multiple sclerosis or diabetes; if they had a weakened immune system as a result of cancer treatment in the previous 2 years; and if their body mass index was 40 or above. Moreover, we classified as CV respondents who had been contacted by their GP/NHS and had been advised to shield. To better disentangle the role of age and clinical vulnerability, we did not classify those aged 70 and older as CV just because of age, but rather used age groups as an independent variable in analysis.

\section{Health and social well-being}

We considered two main areas of outcomes during the COVID-19 pandemic: health, and social relationships and social engagement ('social well-being'). To consider changes, the choice of the outcome measures focused on variables collected in both surveys used for the longitudinal analysis (ie, wave 9 and the COVID-19 substudy). We included as health respondent's selfrated health (SRH, 'fair or poor' vs better) and physical activity (less than usual vs same or more during the pandemic). Symptoms of depression were measured by an abbreviated version of the validated Center for Epidemiologic Studies Depression Scale (CES-D), ${ }^{32}$ with respondents reporting $3+$ depressive symptoms in the week prior to interview classified as depressed. Anxiety was monitored with the Generalized Anxiety Disorder (GAD-7) assessment, a well-validated tool used to screen for generalised anxiety disorder in clinical practice and research, ${ }^{33}$ with a threshold of 10 used to define significant symptoms. Finally, we considered both subjective QoL evaluated using the Control, Autonomy, Self-realization and Pleasure (CASP) -12 scale $^{34}$ and two measures of personal well-being (life satisfaction and happiness) assessed using the Office for National Statistics (ONS) well-being scales, ${ }^{35}$ with higher scores indicating greater well-being.

To capture social well-being, we included: whether the participant volunteered during the coronavirus outbreak; loneliness using the short version of the Revised UCLA Loneliness Scale with scores of 6 and higher indicating greater loneliness ${ }^{36}$; and two measures of social contacts indicating less than weekly contacts with family and friends by phone or by more modern technology (texts/emails/video calls). Also, we considered whether respondents received formal or informal care at home in the previous month, and whether their care needs were met all the time or not.

Of the health and social vulnerability measures collected in the COVID-19 substudy, the following were also collected at wave 9 (and were coded likewise): SRH, depression, QoL, well-being, loneliness and social contacts. For GAD-7-not included in previous waves-analyses were adjusted for ratings on the ONS anxiety scale. Social contacts in previous waves did not consider video calls. Finally, receipt of formal care was only available for those who reported disabilities. 
Table 1 Percent (and n) distribution of socioeconomic and demographic characteristics, health and social well-being, by clinical vulnerability to COVID-19

\begin{tabular}{|c|c|c|c|c|}
\hline & All sample & Clinically not vulnerable & Clinically vulnerable & $P$ value \\
\hline \multicolumn{5}{|l|}{ Socioeconomic and demographic characteristics } \\
\hline Mean age (SD) & 67.0 & $65.4(10.06)$ & $69.4(10.88)$ & $<0.001$ \\
\hline Female & 52.7 & $53.3(1984)$ & $51.8(1205)$ & 0.392 \\
\hline Non-White & 7.1 & $5.8(107)$ & $9.1(114)$ & 0.007 \\
\hline In lowest wealth quintile & 19.4 & $15.7(367)$ & $25.2(363)$ & $<0.001$ \\
\hline 2nd wealth quintile & 19.8 & $17.9(506)$ & $22.7(454)$ & \\
\hline 3rd wealth quintile & 20.4 & $20.3(705)$ & $20.4(489)$ & \\
\hline 4th wealth quintile & 20.4 & $22.5(863)$ & $17.3(444)$ & \\
\hline In highest wealth quintile & 20.0 & $23.6(918)$ & $14.4(398)$ & \\
\hline Mean income in $\mathrm{f} 10000$ (SD) & 2.31 & $2.52(2.31)$ & $1.99(1.65)$ & $<0.001$ \\
\hline Married/cohabiting & 65.9 & $69.5(2372)$ & $60.2(1338)$ & $<0.001$ \\
\hline Mean people in household (SD) & 2.16 & $2.20(1.01)$ & $2.09(1.04)$ & 0.010 \\
\hline High education & 20.5 & $24.3(950)$ & $14.8(409)$ & $<0.001$ \\
\hline Medium education & 49.1 & $50.8(1694)$ & $46.3(1059)$ & \\
\hline Low education & 30.4 & $24.9(716)$ & $38.9(686)$ & \\
\hline \multicolumn{5}{|l|}{ Health } \\
\hline Poor self-rated health & 25.6 & $15.7(474)$ & $40.9(808)$ & $<0.001$ \\
\hline Less physically active & 35.5 & $32.5(1091)$ & $40.2(893)$ & $<0.001$ \\
\hline 3+ CES-D depressive symptoms & 27.9 & $22.7(743)$ & $35.9(712)$ & $<0.001$ \\
\hline 10+ GAD-7 anxiety & 9.6 & $6.5(192)$ & $14.4(235)$ & $<0.001$ \\
\hline Happiness (SD) & 7.52 & $7.70(1.99)$ & $7.22(2.14)$ & $<0.001$ \\
\hline Life satisfaction (SD) & 7.38 & $7.65(2.00)$ & $6.94(2.51)$ & $<0.001$ \\
\hline Mean CASP-12 score (SD) & 26.1 & $27.4(5.66)$ & $24.0(6.77)$ & $<0.001$ \\
\hline \multicolumn{5}{|l|}{ Social well-being } \\
\hline Voluntary work & 16.8 & $18.7(638)$ & $13.8(316)$ & $<0.001$ \\
\hline High loneliness (UCLA) & 23.3 & $19.9(653)$ & $28.5(566)$ & $<0.001$ \\
\hline Less than weekly contacts (phone) & 9.9 & $9.7(301)$ & $10.3(206)$ & 0.556 \\
\hline Less than weekly contacts (email/text/video call) & 15.7 & $13.0(419)$ & $19.9(406)$ & $<0.001$ \\
\hline Has received formal help & 9.1 & $4.6(164)$ & $16.2(341)$ & 0.001 \\
\hline Unmet care needs & 9.4 & $4.9(163)$ & $16.4(305)$ & $<0.001$ \\
\hline Shielding & 16.1 & $8.1(328)$ & $28.5(614)$ & $<0.001$ \\
\hline Total respondents & 5585 & $60.8(3413)$ & $39.2(2172)$ & \\
\hline
\end{tabular}

Source: ELSA, COVID-19 substudy wave 1 (June/July 2020) and wave 9 (2018/2019). Weighted data. P values refer to the relevant statistical tests (ie, t-test, ANOVA or $\chi^{2}$ tests). ANOVA, analysis of variance; CASP-12, Control, Autonomy, Self-realization and Pleasure-12 scale; CES-D, Center for Epidemiologic Studies Depression Scale; ELSA, English Longitudinal Study of Ageing; GAD-7, Generalized Anxiety Disorder-7.

\section{Covariates}

All analyses controlled for a wide range of demographic and socioeconomic characteristics. Age was modelled as a categorical variable, distinguishing those aged 52-59, 60-69, 70-79 and $80+$. We also considered both the number of people living in the household during the pandemic, and whether respondents had a spouse/partner. As people in minority ethnic groups have been shown to be more vulnerable to severe illness and mortality from COVID-19 (likely to reflect an increased risk of exposure to the virus as well as social and health inequalities, which are the product of structural and institutional racism and racial discrimination ${ }^{3738}$ ), we controlled for ethnicity. Due to data constraints in ELSA, we were only able to consider a dichotomous variable (White vs non-White participants). Educational level was classified as low, middle or high using the International Standard Classification of Education. We categorised respondents by quintiles of wealth (total net non-pension non-housing wealth) and accounted for their equivalised total income (from paid work, state benefits, pensions and assets). ${ }^{39}$ Respondents were categorised as 'shielding' if they reported staying at home at all times in the week prior the interview, that is, not leaving home for any reason, not going out to buy food and not seeing people outside of their household.

\section{Statistical analysis}

We investigated the longitudinal associations between $\mathrm{CV}$ and health and social well-being using logistic or linear models depending on the outcome and adjusting for socioeconomic and demographic characteristics as well as for the prepandemicrelevant health or social well-being (except for changes in physical activity and whether care needs were met, not measured at wave 9). Model A focuses on CV (controlling for age groups) whereas model B examines the interaction between age group and CV. Given the links between CV, age and shielding, we also repeated all analyses considering the interaction between $\mathrm{CV}$ and 
shielding (while controlling for age groups). All analyses were performed using Stata V.15. Cross-sectional and longitudinal sampling weights were employed to account for different probabilities of being included in the sample and for non-response to the survey.

\section{RESULTS}

\section{Descriptive statistics}

Overall, as of July 2020, 39\% of the ELSA sample were CV, with higher prevalence in older age (see online supplemental figure $\mathrm{S} 1$ for details). The characteristics of the respondents are shown in table 1. Overall, older people, widowed and in more deprived socioeconomic positions (low educational qualifications, lowest wealth quintiles and income) were more likely to be classified as $\mathrm{CV}$. The associations between socioeconomic and demographic characteristics and CV remained significant also in the fully adjusted model (see online supplemental table S1). All health vulnerabilities and most of the social risks described above were also more prevalent among CV respondents. However, $\mathrm{CV}$ respondents were more likely to be in worse health and to report lower social well-being even before the pandemic (see online supplemental tables S2 and S3, respectively) endorsing the importance of taking prepandemic levels into account as covariates when analysing experience during the COVID-19 pandemic. Results in online supplemental tables S2 and S3 also show that, particularly for prepandemic health, the interaction between clinical vulnerability and broad age groups was significant, suggesting that $\mathrm{CV}$ compounds age-related risks of poor health outcomes.

\section{Clinical vulnerability and age groups}

Table 2 shows the results from logistic and linear multivariate regression models which investigated longitudinal associations between CV and health during the pandemic (in June/July 2020), while adjusting for the prepandemic health. Even accounting for prepandemic health, results show that, with the exception of life satisfaction, CV respondents were more likely during the pandemic to report worse health outcomes. Compared with those aged 70-79, respondents in their 50s and 60s were more likely to be depressed and anxious, and to have lower levels of happiness, whereas respondents aged $80+$ were more likely to increase their life satisfaction (model A). CV is shown to compound age-related risks of poorer outcomes (model B). For instance, compared with respondents in the same age group but without $\mathrm{CV}$, those $\mathrm{CV}$ aged 60-79 were more likely to report poor SRH, lower levels of physical activity, depression, anxiety

Table 2 Fully adjusted ORs and $\beta$ coefficients (with 95\% Cls) of the relationship between clinical vulnerability to COVID-19 (CV) and health during the pandemic, controlling for prepandemic health, socioeconomic and demographic characteristics

\begin{tabular}{|c|c|c|c|c|c|c|c|}
\hline & Poor SRH & $\begin{array}{l}\text { Less physical } \\
\text { activity }\end{array}$ & $\begin{array}{l}\text { Depressed } \\
\text { (CES-D) }\end{array}$ & $\begin{array}{c}\text { QoL } \\
\text { (CASP-12) } \dagger\end{array}$ & Happinesst & Satisfactiont & $\begin{array}{c}\text { Anxiety } \\
(\text { GAD-7)†‡ }\end{array}$ \\
\hline \multicolumn{8}{|l|}{ Model A } \\
\hline $\mathrm{CV}$ & $\begin{array}{c}1.93^{* * *} \\
(1.57 \text { to } 2.36)\end{array}$ & $\begin{array}{c}1.41^{* * *} \\
(1.21 \text { to } 1.64)\end{array}$ & $\begin{array}{c}1.55^{* * *} \\
(1.30 \text { to } 1.85)\end{array}$ & $\begin{array}{c}-0.751^{* *} \\
(-1.08 \text { to } 0.41)\end{array}$ & $\begin{array}{c}-0.152^{*} \\
(-0.29 \text { to }-0.01)\end{array}$ & $\begin{array}{c}-0.111 \\
(-0.24 \text { to } 0.04)\end{array}$ & $\begin{array}{c}1.85^{* * *} \\
\text { (1.39 to } 2.47)\end{array}$ \\
\hline $52-59$ & $\begin{array}{c}0.81 \\
\text { (0.61 to } 1.09)\end{array}$ & $\begin{array}{c}1.01 \\
\text { (0.81 to } 1.25)\end{array}$ & $\begin{array}{c}1.31^{* *} \\
\text { (1.03 to } 1.67)\end{array}$ & $\begin{array}{c}-0.302 \\
(-0.76 \text { to } 0.15)\end{array}$ & $\begin{array}{c}-0.064 \\
(-0.25 \text { to } 0.13)\end{array}$ & $\begin{array}{c}-0.065 \\
(-0.26 \text { to } 0.13)\end{array}$ & $\begin{array}{c}1.54^{*} \\
\text { (1.01 to } 2.37 \text { ) }\end{array}$ \\
\hline $60-69$ & $\begin{array}{c}0.96 \\
\text { (0.77 to } 1.20)\end{array}$ & $\begin{array}{c}0.93 \\
\text { (0.79 to } 1.09)\end{array}$ & $\begin{array}{c}1.26^{* *} \\
\text { (1.03 to } 1.54)\end{array}$ & $\begin{array}{c}0.071 \\
(-0.30 \text { to } 0.44)\end{array}$ & $\begin{array}{c}-0.151^{*} \\
(-0.30 \text { to }-0.01)\end{array}$ & $\begin{array}{c}-0.095 \\
(-0.25 \text { to } 0.06)\end{array}$ & $\begin{array}{c}1.86^{* * *} \\
\text { (1.32 to } 2.62)\end{array}$ \\
\hline $70-79$ & Ref & Ref & Ref & Ref & Ref & Ref & Ref \\
\hline $80+$ & $\begin{array}{c}0.98 \\
\text { (0.76 to } 1.27 \text { ) }\end{array}$ & $\begin{array}{c}0.99 \\
\text { (0.82 to } 1.20)\end{array}$ & $\begin{array}{c}0.98 \\
\text { (0.76 to } 1.27)\end{array}$ & $\begin{array}{c}-0.312 \\
(-0.75 \text { to } 0.12)\end{array}$ & $\begin{array}{c}0.146 \\
(-0.03 \text { to } 0.32)\end{array}$ & $\begin{array}{c}0.216^{*} \\
(0.03 \text { to } 0.41)\end{array}$ & $\begin{array}{c}0.74 \\
\text { (0.46 to } 1.18)\end{array}$ \\
\hline \multicolumn{8}{|l|}{ Model B } \\
\hline 52-59, not CV & $\begin{array}{c}0.94 \\
\text { (0.65 to } 1.34 \text { ) }\end{array}$ & $\begin{array}{c}1.17 \\
\text { (0.91 to } 1.51)\end{array}$ & $\begin{array}{c}1.31 \\
\text { (0.98 to } 1.75)\end{array}$ & $\begin{array}{c}-0.396 \\
(-0.91 \text { to } 0.12)\end{array}$ & $\begin{array}{c}-0.082 \\
(-0.29 \text { to } 0.13)\end{array}$ & $\begin{array}{c}-0.144 \\
(-0.36 \text { to } 0.07)\end{array}$ & $\begin{array}{c}1.50 \\
\text { (0.85 to } 2.66)\end{array}$ \\
\hline 60-69, not CV & $\begin{array}{c}1.09 \\
\text { (0.80 to } 1.47)\end{array}$ & $\begin{array}{c}0.99 \\
\text { (0.80 to } 1.23)\end{array}$ & $\begin{array}{c}1.04 \\
\text { (0.81 to } 1.34)\end{array}$ & $\begin{array}{c}0.147 \\
(-0.25 \text { to } 0.55)\end{array}$ & $\begin{array}{c}-0.103 \\
(-0.26 \text { to } 0.06)\end{array}$ & $\begin{array}{c}-0.050 \\
(-0.20 \text { to } 0.10)\end{array}$ & $\begin{array}{c}1.43 \\
\text { (0.88 to } 2.32 \text { ) }\end{array}$ \\
\hline 70-79, not CV & Ref & Ref & Ref & Ref & Ref & Ref & Ref \\
\hline $80+$, not CV & $\begin{array}{c}1.12 \\
\text { (0.75 to } 1.67)\end{array}$ & $\begin{array}{c}1.06 \\
\text { (0.81 to } 1.39)\end{array}$ & $\begin{array}{c}0.89 \\
\text { (0.64 to } 1.23)\end{array}$ & $\begin{array}{c}-0.530^{*} \\
(-1.05 \text { to }-0.01)\end{array}$ & $\begin{array}{c}0.113 \\
(-0.11 \text { to } 0.33)\end{array}$ & $\begin{array}{c}0.159 \\
(-0.08 \text { to } 0.40)\end{array}$ & $\begin{array}{c}0.79 \\
\text { (0.41 to } 1.53)\end{array}$ \\
\hline $52-59$, CV & $\begin{array}{c}1.65^{*} \\
\text { (1.04 to } 2.61)\end{array}$ & $\begin{array}{c}1.33 \\
\text { (0.92 to } 1.90)\end{array}$ & $\begin{array}{c}1.94^{* *} \\
(1.30 \text { to } 2.90)\end{array}$ & $\begin{array}{c}-0.933^{*} \\
(-1.72 \text { to }-0.15)\end{array}$ & $\begin{array}{c}-0.150 \\
(-0.51 \text { to } 0.21)\end{array}$ & $\begin{array}{c}-0.032 \\
(-0.35 \text { to } 0.29)\end{array}$ & $\begin{array}{c}1.95^{*} \\
\text { (1.02 to } 3.72)\end{array}$ \\
\hline $60-69, \mathrm{CV}$ & $\begin{array}{c}2.02^{* * *} \\
\text { (1.45 to } 2.81)\end{array}$ & $\begin{array}{c}1.46^{* *} \\
\text { (1.13 to } 1.89)\end{array}$ & $\begin{array}{c}1.86^{* * *} \\
\text { (1.37 to } 2.54)\end{array}$ & $\begin{array}{c}-0.908^{* *} \\
(-1.56 \text { to }-0.25)\end{array}$ & $\begin{array}{c}-0.375^{* *} \\
(-0.65 \text { to }-0.10)\end{array}$ & $\begin{array}{c}-0.329^{*} \\
(-0.60 \text { to }-0.06)\end{array}$ & $\begin{array}{c}3.94^{* * *} \\
(2.47 \text { to } 6.29)\end{array}$ \\
\hline 70-79, CV & $\begin{array}{c}2.31^{* * *} \\
(1.76 \text { to } 3.03)\end{array}$ & $\begin{array}{c}1.66^{* * *} \\
(1.36 \text { to } 2.03)\end{array}$ & $\begin{array}{c}1.50^{* * *} \\
(1.18 \text { to } 1.89)\end{array}$ & $\begin{array}{c}-0.815^{* * *} \\
(-1.26 \text { to }-0.37)\end{array}$ & $\begin{array}{c}-0.135 \\
(-0.30 \text { to } 0.03)\end{array}$ & $\begin{array}{c}-0.137 \\
(-0.32 \text { to } 0.05)\end{array}$ & $\begin{array}{c}1.71^{*} \\
\text { (1.08 to } 2.70)\end{array}$ \\
\hline $80+, \mathrm{CV}$ & $\begin{array}{c}2.06^{* * *} \\
\text { (1.46 to } 2.91)\end{array}$ & $\begin{array}{c}1.53^{* *} \\
\text { (1.18 to } 1.98)\end{array}$ & $\begin{array}{c}1.20 \\
\text { (0.86 to } 1.68)\end{array}$ & $\begin{array}{c}-0.934^{* *} \\
(-1.57 \text { to }-0.29)\end{array}$ & $\begin{array}{c}0.037 \\
(-0.22 \text { to } 0.30)\end{array}$ & $\begin{array}{c}0.135 \\
(-0.14 \text { to } 0.41)\end{array}$ & $\begin{array}{c}1.24 \\
\text { (0.67 to } 2.31)\end{array}$ \\
\hline Observations & 5310 & 5392 & 5306 & 5004 & 4832 & 4939 & 4912 \\
\hline
\end{tabular}

Source: ELSA, COVID-19 substudy wave 1 (June/July 2020) and wave 9 (2018/2019). All models control for gender, ethnicity, partnership status, number of respondents in the household, education, wealth quintiles and income. Each model also controls for the relevant health variable at baseline (except less physical activity). All continuous measures are coded such that higher values mean better outcomes. Values in brackets show the $95 \%$ Cls. Weighted data.

${ }^{*} \mathrm{P}<0.05 ;{ }^{* *} \mathrm{p}<0.01 ;{ }^{* * *} \mathrm{p}<0.001$.

tQuestions in wave 9 were asked in the self-completion questionnaire.

¥This model controls for baseline anxiety measure using the ONS question.

CASP-12, Control, Autonomy, Self-realization and Pleasure-12 scale; CES-D, Center for Epidemiologic Studies Depression Scale; CV, clinically vulnerable; ELSA, English Longitudinal Study of Ageing; GAD-7, Generalized Anxiety Disorder-7; ONS, Office for National Statistics; QoL, quality of life; SRH, self-rated health. 
Table 3 Fully adjusted ORs (with 95\% CIs) of the relationship between clinical vulnerability to COVID-19 (CV) and social well-being during the pandemic, controlling for prepandemic social well-being, socioeconomic and demographic characteristics

\begin{tabular}{|c|c|c|c|c|c|c|}
\hline & Voluntary work & High loneliness $t$ & $\begin{array}{l}\text { Less than weekly } \\
\text { contacts (phone) } \dagger\end{array}$ & $\begin{array}{l}\text { Less than weekly contacts } \\
\text { (text/email) } t\end{array}$ & Received care & Unmet care needs \\
\hline \multicolumn{7}{|l|}{ Model A } \\
\hline $\mathrm{CV}$ & $\begin{array}{c}0.89 \\
\text { (0.73 to } 1.10)\end{array}$ & $\begin{array}{c}1.28^{* *} \\
(1.04 \text { to } 1.59)\end{array}$ & $\begin{array}{c}1.06 \\
\text { (0.79 to } 1.44)\end{array}$ & $\begin{array}{c}1.12 \\
(0.85 \text { to } 1.47)\end{array}$ & $\begin{array}{c}2.78^{* * *} \\
(2.14 \text { to } 3.61)\end{array}$ & $\begin{array}{c}3.05^{* * *} \\
(2.27 \text { to } 4.10)\end{array}$ \\
\hline $52-59$ & $\begin{array}{c}1.70^{* * *} \\
(1.27 \text { to } 2.27)\end{array}$ & $\begin{array}{c}1.11 \\
(0.84 \text { to } 1.48)\end{array}$ & $\begin{array}{c}1.20 \\
\text { (0.80 to } 1.78)\end{array}$ & $\begin{array}{c}0.55^{* * *} \\
(0.37 \text { to } 0.81)\end{array}$ & $\begin{array}{c}0.24^{* * *} \\
(0.13 \text { to } 0.43)\end{array}$ & $\begin{array}{c}0.98 \\
\text { (0.65 to } 1.49)\end{array}$ \\
\hline $60-69$ & $\begin{array}{c}1.57^{* \star *} \\
(1.26 \text { to } 1.95)\end{array}$ & $\begin{array}{c}1.07 \\
\text { (0.85 to } 1.35)\end{array}$ & $\begin{array}{c}1.26 \\
\text { (0.94 to } 1.70)\end{array}$ & $\begin{array}{c}0.72^{* * *} \\
(0.53 \text { to } 0.98)\end{array}$ & $\begin{array}{c}0.55^{* * *} \\
(0.41 \text { to } 0.75)\end{array}$ & $\begin{array}{c}0.83 \\
\text { (0.59 to } 1.17)\end{array}$ \\
\hline $70-79$ & Ref & Ref & Ref & Ref & Ref & Ref \\
\hline $80+$ & $\begin{array}{c}1.03 \\
\text { (0.77 to } 1.36)\end{array}$ & $\begin{array}{c}0.78 \\
\text { (0.59 to } 1.03)\end{array}$ & $\begin{array}{c}1.01 \\
\text { (0.67 to } 1.54)\end{array}$ & $\begin{array}{c}2.31^{* * *} \\
(1.70 \text { to } 3.13)\end{array}$ & $\begin{array}{l}2.36^{* * *} \\
(1.78 \text { to } 3.14)\end{array}$ & $\begin{array}{c}1.44^{*} \\
\text { (1.06 to } 1.96)\end{array}$ \\
\hline \multicolumn{7}{|l|}{ Model B } \\
\hline 52-59, not CV & $\begin{array}{c}1.75^{* *} \\
(1.25 \text { to } 2.44)\end{array}$ & $\begin{array}{c}1.22 \\
(0.88 \text { to } 1.69)\end{array}$ & $\begin{array}{c}1.18 \\
(0.74 \text { to } 1.88)\end{array}$ & $\begin{array}{c}0.81 \\
(0.48 \text { to } 1.36)\end{array}$ & $\begin{array}{c}0.15^{* * *} \\
(0.06 \text { to } 0.38)\end{array}$ & $\begin{array}{c}0.52^{*} \\
(0.29 \text { to } 0.93)\end{array}$ \\
\hline 60-69, not CV & $\begin{array}{c}1.60^{* * *} \\
(1.22 \text { to } 2.10)\end{array}$ & $\begin{array}{c}0.99 \\
\text { (0.74 to } 1.34)\end{array}$ & $\begin{array}{c}1.34 \\
\text { (0.91 to } 1.97)\end{array}$ & $\begin{array}{c}0.80 \\
(0.54 \text { to } 1.20)\end{array}$ & $\begin{array}{c}0.49^{*} \\
(0.28 \text { to } 0.85)\end{array}$ & $\begin{array}{c}0.51^{*} \\
(0.29 \text { to } 0.92)\end{array}$ \\
\hline 70-79, not CV & Ref & Ref & Ref & Ref & Ref & Ref \\
\hline $80+$, not CV & $\begin{array}{c}1.14 \\
\text { (0.79 to } 1.66)\end{array}$ & $\begin{array}{c}0.92 \\
\text { (0.64 to } 1.32)\end{array}$ & $\begin{array}{c}1.28 \\
(0.73 \text { to } 2.25)\end{array}$ & $\begin{array}{c}3.17^{* * *} \\
(2.13 \text { to } 4.73)\end{array}$ & $\begin{array}{c}3.14^{* * *} \\
(2.02 \text { to } 4.90)\end{array}$ & $\begin{array}{c}1.90^{* *} \\
\text { (1.19 to } 3.04)\end{array}$ \\
\hline $52-59$, CV & $\begin{array}{c}1.61^{*} \\
(1.02 \text { to } 2.54)\end{array}$ & $\begin{array}{c}1.27 \\
\text { (0.76 to } 2.13)\end{array}$ & $\begin{array}{c}1.49 \\
\text { (0.77 to } 2.86)\end{array}$ & $\begin{array}{c}0.62 \\
\text { (0.26 to } 1.51)\end{array}$ & $\begin{array}{c}0.89 \\
\text { (0.42 to } 1.88)\end{array}$ & $\begin{array}{c}2.99 * * * \\
(1.71 \text { to } 5.22)\end{array}$ \\
\hline $60-69, \mathrm{CV}$ & $\begin{array}{c}1.47^{*} \\
(1.05 \text { to } 2.07)\end{array}$ & $\begin{array}{c}1.65^{* *} \\
(1.17 \text { to } 2.31)\end{array}$ & $\begin{array}{c}1.35 \\
\text { (0.85 to } 2.14)\end{array}$ & $\begin{array}{c}1.19 \\
\text { (0.72 to } 1.96)\end{array}$ & $\begin{array}{c}1.73^{*} \\
(1.12 \text { to } 2.65)\end{array}$ & $\begin{array}{c}2.45^{* * *} \\
(1.54 \text { to } 3.88)\end{array}$ \\
\hline $70-79, \mathrm{CV}$ & $\begin{array}{c}0.96 \\
\text { (0.72 to } 1.28)\end{array}$ & $\begin{array}{c}1.35^{*} \\
(1.02 \text { to } 1.78)\end{array}$ & $\begin{array}{c}1.16 \\
\text { (0.78 to } 1.73)\end{array}$ & $\begin{array}{c}1.45^{*} \\
\text { (1.03 to } 2.04)\end{array}$ & $\begin{array}{c}2.89^{* * *} \\
(2.00 \text { to } 4.18)\end{array}$ & $\begin{array}{c}2.28^{* * *} \\
(1.58 \text { to } 3.28)\end{array}$ \\
\hline $80+, \mathrm{CV}$ & $\begin{array}{c}0.88 \\
\text { (0.58 to } 1.32 \text { ) }\end{array}$ & $\begin{array}{c}0.92 \\
\text { (0.61 to } 1.36)\end{array}$ & $\begin{array}{c}0.93 \\
\text { (0.51 to } 1.67)\end{array}$ & $\begin{array}{c}2.53^{* * *} \\
(1.71 \text { to } 3.75)\end{array}$ & $\begin{array}{c}5.91^{* * *} \\
\text { (3.94 to } 8.86)\end{array}$ & $\begin{array}{c}2.88^{* * *} \\
(1.90 \text { to } 4.37)\end{array}$ \\
\hline Observations & 5376 & 5053 & 4513 & 4055 & 5400 & 5398 \\
\hline
\end{tabular}

Source: ELSA, COVID-19 substudy wave 1 (June/July 2020) and wave 9 (2018/2019). All models control for gender, ethnicity, partnership status, number of respondents in the household, education, wealth quintiles and income. Each model also controls for the relevant social well-being variable at baseline (except for 'unmet care needs'). Values in brackets show the $95 \%$ Cls. Weighted data.

${ }^{*} \mathrm{P}<0.05 ;{ }^{* *} \mathrm{p}<0.01 ;{ }^{* * *} \mathrm{p}<0.001$.

tQuestions in wave 9 were asked in the self-completion questionnaire.

CV, clinically vulnerable; ELSA, English Longitudinal Study of Ageing.

and lower QoL, and those CV aged 60-69 to report lower happiness and life satisfaction.

Table 3 shows the results from similar analyses which focus on social well-being controlling for prepandemic measures. During the pandemic, CV respondents were more likely to report high loneliness, receipt of care and unmet care needs (model A), particularly in younger age groups (model B). For volunteering, results suggest that changes during the pandemic were mostly driven by age regardless of whether respondents were $\mathrm{CV}$ or not. Finally, results show that those CV in their 70s were less likely to communicate at least weekly with their friends and family via emails/texts/video calls than respondents in the same age group without clinical vulnerabilities, whereas among people aged $80+$ these social contacts reduced regardless of their CV status.

\section{Clinical vulnerability and shielding}

'At risk' and older individuals were advised to stay at home and limit their contacts as much as possible. Overall, during the COVID-19 substudy, 29\% of CV respondents reported shielding compared with only 1 in 12 among those with no clinical vulnerabilities (see table 1 ), with percentages increasing with age (see online supplemental figure S2 for details). For instance, among those aged $60-69,5 \%$ were shielding if they were not CV compared with $25 \%$ if they were CV. Among those aged 80 and older, the gap reduced but the percentage of respondents shielding was $\sim 13 \%$ higher among $\mathrm{CV}$ than those with no CV ( $42 \%$ vs $29 \%$ respectively).

Table 4 shows the associations between the interaction of CV with shielding and health outcomes during the COVID-19 pandemic, while accounting for age groups, prepandemic health, as well as socioeconomic and demographic characteristics. For all outcomes considered, CV respondents who were shielding reported worse health compared with those not CV and not shielding, and generally fared worse also compared with those CV not shielding. Finally, respondents who were shielding (despite not being CV) were more likely to report poor SRH, depression and lower levels of physical exercise compared with those not CV and not shielding. When the interaction of CV and shielding is considered, age itself overall does not play an important role. However, results suggest that those in their 50s and 60 s were more likely to be depressed, anxious and to report lower happiness compared with those aged 70-79.

Table 5 shows the results of similar analyses for social wellbeing. CV respondents and shielding were more likely to report higher levels of loneliness, receipt of care and unmet needs compared with respondents not CV and not shielding; they were, unsurprisingly, also less likely to volunteer. It was those in their 50 s and 60 s who were more likely to volunteer during the 
Table 4 Fully adjusted ORs and $\beta$ coefficients (with 95\% Cls) of the relationship between the interaction of clinical vulnerability to COVID-19 (CV) with shielding and health during the pandemic, controlling for prepandemic health, socioeconomic and demographic characteristics

\begin{tabular}{|c|c|c|c|c|c|c|c|}
\hline & Poor SRH & $\begin{array}{l}\text { Less physical } \\
\text { activity }\end{array}$ & $\begin{array}{l}\text { Depressed } \\
\text { (CES-D) }\end{array}$ & $\begin{array}{c}\text { QoL } \\
\text { (CASP-12)† }\end{array}$ & Happiness $†$ & Satisfactiont & $\begin{array}{c}\text { Anxiety } \\
\text { (GAD-7)†‡ }\end{array}$ \\
\hline Not $\mathrm{CV}$, not shielding & Ref & Ref & Ref & Ref & Ref & Ref & Ref \\
\hline Not $\mathrm{CV}$, shielding & $\begin{array}{c}1.49^{*} \\
\text { (1.01 to } 2.21)\end{array}$ & $\begin{array}{c}1.44^{*} \\
(1.07 \text { to } 1.96)\end{array}$ & $\begin{array}{c}1.78^{* *} \\
(1.25 \text { to } 2.54)\end{array}$ & $\begin{array}{c}-0.345 \\
(-0.97 \text { to } 0.28)\end{array}$ & $\begin{array}{c}-0.280 \\
(-0.58 \text { to } 0.02)\end{array}$ & $\begin{array}{c}-0.235 \\
(-0.53 \text { to } 0.06)\end{array}$ & $\begin{array}{c}1.05 \\
\text { (0.44 to } 2.46)\end{array}$ \\
\hline $\mathrm{CV}$, not shielding & $\begin{array}{c}1.63^{* * *} \\
(1.29 \text { to } 2.06)\end{array}$ & $\begin{array}{c}1.31^{* *} \\
(1.10 \text { to } 1.55)\end{array}$ & $\begin{array}{c}1.49^{* * *} \\
(1.22 \text { to } 1.82)\end{array}$ & $\begin{array}{c}-0.517^{* *} \\
(-0.89 \text { to }-0.15)\end{array}$ & $\begin{array}{c}-0.113 \\
(-0.26 \text { to } 0.04)\end{array}$ & $\begin{array}{c}-0.065 \\
(-0.22 \text { to } 0.09)\end{array}$ & $\begin{array}{c}1.58^{* *} \\
\text { (1.13 to } 2.19)\end{array}$ \\
\hline $\mathrm{CV}$, shielding & $\begin{array}{c}3.64^{* * *} \\
(2.70 \text { to } 4.90)\end{array}$ & $\begin{array}{c}2.00^{* * *} \\
\text { (1.58 to } 2.52)\end{array}$ & $\begin{array}{c}2.22^{* * *} \\
\text { (1.67 to } 2.96)\end{array}$ & $\begin{array}{c}-1.594^{* * *} \\
(-2.24 \text { to }-0.94)\end{array}$ & $\begin{array}{c}-0.370^{* *} \\
(-0.65 \text { to }-0.09)\end{array}$ & $\begin{array}{c}-0.299^{*} \\
(-0.55 \text { to }-0.05)\end{array}$ & $\begin{array}{c}2.82^{* * *} \\
(1.80 \text { to } 4.41)\end{array}$ \\
\hline $50-59$ & $\begin{array}{c}0.88 \\
\text { (0.66 to } 1.18)\end{array}$ & $\begin{array}{c}1.05 \\
\text { (0.85 to } 1.31)\end{array}$ & $\begin{array}{c}1.40^{* *} \\
(1.09 \text { to } 1.80)\end{array}$ & $\begin{array}{c}-0.367 \\
(-0.83 \text { to } 0.09)\end{array}$ & $\begin{array}{c}-0.093 \\
(-0.29 \text { to } 0.10)\end{array}$ & $\begin{array}{c}-0.089 \\
(-0.28 \text { to } 0.10)\end{array}$ & $\begin{array}{c}1.61^{*} \\
\text { (1.04 to } 2.49)\end{array}$ \\
\hline $60-69$ & $\begin{array}{c}1.01 \\
\text { (0.81 to } 1.26)\end{array}$ & $\begin{array}{c}0.96 \\
\text { (0.81 to } 1.13)\end{array}$ & $\begin{array}{c}1.27^{*} \\
\text { (1.02 to } 1.54)\end{array}$ & $\begin{array}{c}0.032 \\
(-0.34 \text { to } 0.40)\end{array}$ & $\begin{array}{c}-0.171^{*} \\
(-0.32 \text { to }-0.02)\end{array}$ & $\begin{array}{c}-0.112 \\
(-0.27 \text { to } 0.04)\end{array}$ & $\begin{array}{c}1.90^{* * *} \\
\text { (1.35 to } 2.69)\end{array}$ \\
\hline 70-79 & Ref & Ref & Ref & Ref & Ref & Ref & Ref \\
\hline $80+$ & $\begin{array}{c}0.91 \\
\text { (0.70 to } 1.19)\end{array}$ & $\begin{array}{c}0.95 \\
\text { (0.78 to } 1.15)\end{array}$ & $\begin{array}{c}0.79 \\
(0.62 \text { to } 1.01)\end{array}$ & $\begin{array}{c}-0.230 \\
(-0.67 \text { to } 0.21)\end{array}$ & $\begin{array}{c}0.175 \\
(-0.00 \text { to } 0.35)\end{array}$ & $\begin{array}{c}0.245^{*} \\
(0.05 \text { to } 0.44)\end{array}$ & $\begin{array}{c}0.70 \\
\text { (0.43 to } 1.14 \text { ) }\end{array}$ \\
\hline Observations & 5343 & 5427 & 5339 & 4862 & 4968 & 5034 & 4941 \\
\hline
\end{tabular}

Source: ELSA, COVID-19 substudy wave 1 (June/July 2020) and wave 9 (2018/2019). All models control for gender, ethnicity, partnership status, number of respondents in the household, education, wealth quintiles and income. Each model also controls for the relevant health variable at baseline (except less physical activity). All continuous measures are coded such that higher values mean better outcomes. Values in brackets show the $95 \% \mathrm{Cls}$. Weighted data.

${ }^{*} \mathrm{P}<0.05 ;{ }^{* *} \mathrm{p}<0.01 ;{ }^{* * *} \mathrm{p}<0.001$

tQuestions in wave 9 were asked in the self-completion questionnaire.

¥This model controls for baseline anxiety measure using the ONS question.

CASP-12, Control, Autonomy, Self-realization and Pleasure-12 scale; CES-D, Center for Epidemiologic Studies Depression Scale; CV, clinically vulnerable; ELSA, English Longitudinal Study of Ageing; GAD-7, Generalized Anxiety Disorder-7; ONS, Office for National Statistics; QoL, quality of life; SRH, self-rated health.

pandemic regardless of their $\mathrm{CV}$ status. Clear age gradients were also found for receipt of care and contacts via texts/emails/video calls, with those aged 80 and older more likely to receive care than those aged 70-79, and to report less than weekly contacts with friends and family using modern technology.

\section{DISCUSSION AND CONCLUSIONS}

CV older people ( $\sim 49 \%$ of those aged 70 and older) were more likely to report worse health and social well-being outcomes during the pandemic compared with participants not $\mathrm{CV}$, even taking into account prepandemic levels of health and well-being. However, changes in health were not uniform across different age groups, with those in their 50s and 60s more likely to report greater deterioration in mental health than those in their 70 s and over 80. Our results also show a complex interplay between $\mathrm{CV}$, age groups and health and social well-being, with CV respondents generally at greater risk of deterioration in health and social well-being compared with those in the same age group but

Table 5 Fully adjusted ORs (with 95\% Cls) of the relationship between the interaction of clinical vulnerability to COVID-19 (CV) with shielding and social well-being during the pandemic, controlling for prepandemic social well-being, socioeconomic and demographic characteristics

\begin{tabular}{|c|c|c|c|c|c|c|}
\hline & Voluntary work & High loneliness $t$ & $\begin{array}{c}\text { Less weekly contacts } \\
\text { (phone) } \dagger\end{array}$ & $\begin{array}{l}\text { Less weekly contacts } \\
\text { (text/email) } \dagger\end{array}$ & Received care & Unmet care needs \\
\hline Not $\mathrm{CV}$, not shielding & Ref & Ref & Ref & Ref & Ref & Ref \\
\hline Not CV, shielding & $\begin{array}{c}0.62^{*} \\
\text { (0.39 to } 0.97 \text { ) }\end{array}$ & $\begin{array}{c}1.05 \\
\text { (0.67 to } 1.66)\end{array}$ & $\begin{array}{c}1.20 \\
\text { (0.65 to } 2.22 \text { ) }\end{array}$ & $\begin{array}{c}1.43 \\
\text { (0.89 to } 2.29)\end{array}$ & $\begin{array}{c}3.14^{* * *} \\
(1.95 \text { to } 5.07)\end{array}$ & $\begin{array}{c}2.26^{* *} \\
\text { (1.38 to } 3.72)\end{array}$ \\
\hline CV, not shielding & $\begin{array}{c}0.95 \\
\text { (0.76 to } 1.19)\end{array}$ & $\begin{array}{c}1.17 \\
\text { (0.92 to } 1.48)\end{array}$ & $\begin{array}{c}1.12 \\
(0.80 \text { to } 1.56)\end{array}$ & $\begin{array}{c}1.18 \\
\text { (0.87 to } 1.61)\end{array}$ & $\begin{array}{c}2.72^{* * *} \\
(2.02 \text { to } 3.64)\end{array}$ & $\begin{array}{c}2.80^{* * *} \\
(1.97 \text { to } 3.98)\end{array}$ \\
\hline CV, shielding & $\begin{array}{c}0.62^{*} \\
\text { (0.43 to } 0.91)\end{array}$ & $\begin{array}{c}1.67^{* *} \\
\text { (1.19 to } 2.37)\end{array}$ & $\begin{array}{c}0.99 \\
\text { (0.64 to } 1.54)\end{array}$ & $\begin{array}{c}1.16 \\
\text { (0.74 to } 1.82)\end{array}$ & $\begin{array}{l}5.80^{* * *} \\
\text { (3.98 to } 8.47 \text { ) }\end{array}$ & $\begin{array}{c}5.41^{* * *} \\
\text { (3.59 to } 8.15)\end{array}$ \\
\hline $50-59$ & $\begin{array}{c}1.63^{* * *} \\
(1.22 \text { to } 2.18)\end{array}$ & $\begin{array}{c}1.14 \\
\text { (0.85 to } 1.52)\end{array}$ & $\begin{array}{c}1.20 \\
\text { (0.81 to } 1.79 \text { ) }\end{array}$ & $\begin{array}{c}0.64^{*} \\
\text { (0.42 to } 0.99)\end{array}$ & $\begin{array}{c}0.27^{* * *} \\
(0.15 \text { to } 0.49)\end{array}$ & $\begin{array}{c}1.10 \\
\text { (0.72 to } 1.68)\end{array}$ \\
\hline $60-69$ & $\begin{array}{c}1.53^{* * *} \\
(1.23 \text { to } 1.90)\end{array}$ & $\begin{array}{c}1.09 \\
\text { (0.86 to } 1.37 \text { ) }\end{array}$ & $\begin{array}{c}1.27 \\
\text { (0.94 to } 1.71)\end{array}$ & $\begin{array}{c}0.73^{*} \\
(0.53 \text { to } 1.00)\end{array}$ & $\begin{array}{c}0.59^{* *} \\
(0.43 \text { to } 0.81)\end{array}$ & $\begin{array}{c}0.87 \\
(0.62 \text { to } 1.23)\end{array}$ \\
\hline $70-79$ & Ref & Ref & Ref & Ref & Ref & Ref \\
\hline $80+$ & $\begin{array}{c}1.08 \\
\text { (0.81 to } 1.45)\end{array}$ & $\begin{array}{c}0.76 \\
\text { (0.57 to } 1.01)\end{array}$ & $\begin{array}{c}1.00 \\
\text { (0.67 to } 1.50)\end{array}$ & $\begin{array}{c}2.25^{* * *} \\
(1.69 \text { to } 3.01)\end{array}$ & $\begin{array}{c}2.20^{* * *} \\
(1.65 \text { to } 2.94)\end{array}$ & $\begin{array}{c}1.34 \\
\text { (0.98 to } 1.84)\end{array}$ \\
\hline Observations & 5340 & 5018 & 4539 & 4055 & 5435 & 5432 \\
\hline
\end{tabular}

Source: ELSA, COVID-19 substudy wave 1 (June/July 2020) and wave 9 (2018/2019). All models control for gender, ethnicity, partnership status, number of respondents in the household, education, wealth quintiles and income. Each model also controls for the relevant social well-being variable at baseline. Values in brackets show the $95 \% \mathrm{Cls}$. Weighted data.

${ }^{*} \mathrm{P}<0.05 ;{ }^{* *} \mathrm{p}<0.01 ; * * * \mathrm{p}<0.001$.

tQuestions in wave 9 were asked in the self-completion questionnaire.

CV, clinically vulnerable; ELSA, English Longitudinal Study of Ageing. 
without clinical vulnerabilities. Moreover, we find a multiplicative effect of shielding and clinical vulnerabilities: although older adults' health and social well-being have been overall impacted by shielding, it was those who were shielding and were CV who reported the most substantial rises in anxiety, depression, poor $\mathrm{SRH}$ and receipt of formal care as well as decreases in well-being and physical activity.

This study draws strength from using longitudinal data from the nationally representative ELSA. It also explored a wide range of health and social well-being outcomes older people faced during the COVID-19 crisis without treating all older people as a homogenous group. Moreover, all analyses took account of levels of health and social well-being measured before the pandemic; results are therefore not merely reflections of preexisting differences. This study also considered the interactive effect of CV and old age as well as that of CV and social isolation. Our contribution, however, should be considered in light of some limitations. Given the design of ELSA which samples only the over-50 population, we could not evaluate associations across the full adult age spectrum, although we were able to consider how the relationship between CV and outcomes varied across and interacted with different broad age groups. Moreover, ELSA suffers from non-random cumulative attrition, an unavoidable problem in longitudinal studies which can only partially be corrected for by using weights in the analysis. Because of the healthy survival effects, we may have selected those with better health than the current population, leading to an underestimate of both the prevalence of $\mathrm{CV}$ and its impact on health and social well-being in later life. Those in care homes are also excluded by the ELSA design. Furthermore, the observational nature of the study means that the influence of unmeasured factors cannot be ruled out. The assessments were carried out during June and July 2020, and there is evidence that emotional distress was greater earlier in the pandemic. ${ }^{17}$ In our models, we controlled for prepandemic socioeconomic characteristics; however, as future waves of ELSA become available, studies should investigate how prepandemic CV impacted wealth, income and labour participation of older participants during the pandemic. Further studies should also examine whether economic and financial disruptions, changes in labour force participation, work hours or working arrangements during the pandemic further exacerbated health inequalities, particularly among those in their $50 \mathrm{~s}$ and 60s. Finally, future studies should investigate in greater depth the interconnection between CV, ethnicity and changes in health and social well-being, further exploring how and to what extent policy responses to the coronavirus pandemic risk further increasing ethnic inequalities in the UK.

Our work contributes to an emerging body of evidence on the indirect effects of the pandemic ${ }^{12-20}$ by focusing on the most at-risk group of people (older and vulnerable people) and by acknowledging the complexities and heterogeneity of older people. Our study also has important implications for public health policy. While CV people were more likely to report a worsening of their health than their counterparts without $\mathrm{CV}$, even in the best scenario of no additional detrimental changes by $\mathrm{CV}$ and age during the pandemic, there were striking prepandemic differences in health and social well-being by CV. Moreover, although so far the focus has been on containing the spread of the disease and saving lives by encouraging shielding and social distancing of the most vulnerable people, policymakers need to be aware that when advised to stay at home, a host of health and social risks for this group, already poor, are likely to be exacerbated. ${ }^{40}$
In summary, our study provides a picture of the broader consequences of the pandemic and shielding policies among older people, and those $\mathrm{CV}$ in particular. While it is important to recognise that the clear aim and main benefit of guidelines focusing on shielding $\mathrm{CV}$ older people is to reduce rates of hospitalisation and death from COVID-19, there may be adverse consequences for their health and social well-being. If the longterm health and social well-being of older people are not to be compromised by stay-at-home advice, policymakers should pay urgent attention to addressing the wider needs particularly of those who are CV. This is especially acute if shielding policies remain in place as strategies to protect individuals at high risk of severe COVID-19 illness and death.

\section{What is already known on this subject}

- Older people with underlying health conditions, even prepandemic, faced challenges in terms of access to healthcare services and social contact and experienced more emotional distress, higher risk of loneliness and poorer quality of life than non-vulnerable individuals.

\section{What this study adds}

- This study shows, using nationally representative data on England, that older people clinically vulnerable (CV) to COVID-19 were more likely to report worse health and social well-being outcomes during the pandemic compared with participants not $\mathrm{CV}$, even taking into account prepandemic levels of health and social well-being.

- Our results also show that, across different age groups, CV respondents were generally at greater risks of deterioration in health and social well-being compared with those in the same age group but without clinical vulnerabilities to COVID-19.

- CV respondents who were shielding reported rises in anxiety, depression, poor self-rated health and receipt of formal care as well as decreases in well-being and physical activity compared with those not $\mathrm{CV}$ and not shielding.

- While shielding policies reduce rates of hospitalisation and death from COVID-19, policymakers need to acknowledge that there may be adverse consequences for the health and social well-being particularly of older CV people shielding.

Acknowledgements The English Longitudinal Study of Ageing was developed by a team of researchers based at University College London, NatCen Social Research, the Institute for Fiscal Studies, the University of Manchester and the University of East Anglia. The data were collected by NatCen Social Research. The data were made available through the UK Data Archive.

Contributors GDG had the initial idea for the study, conducted the analyses, contributed to the study design and drafted the manuscript. DP led the conception and design of the study, co-led the interpretation of the results with GDG and contributed to manuscript revisions. Both authors have read and approved the final version.

Funding The funding is currenlty provided by the National Institute on Aging in the USA, and a consortium of UK Government departments coordinated by the National Institute for Health Research. Funding has also been received by the Economic and Social Research Council.

Disclaimer The developers and funders of ELSA and the Archive do not bear any responsibility for the analyses or interpretations presented here.

Competing interests None declared.

Patient consent for publication Not required. 
Ethics approval ELSA was approved by the London Multicentre Research Ethics Committee (MREC/01/2/91) while the COVID-19 substudy was approved by the UCL Research Ethics Committee.

Provenance and peer review Not commissioned; externally peer reviewed.

Data availability statement Data are available in a public, open-access repository. ELSA data from all waves are available through the UK Data Service (https://www.ukdataservice.ac.uk/) (SN 8688 and 5050). Data can be accessed via https://beta.ukdataservice.ac.uk/datacatalogue/series/series?id=200011. More information on how to access ELSA and on the conditions of use can be found on both the ELSA website (https://www.elsa-project.ac.uk/accessing-elsa-data) and the UK Data Service website.

Supplemental material This content has been supplied by the author(s). It has not been vetted by BMJ Publishing Group Limited (BMJ) and may not have been peer-reviewed. Any opinions or recommendations discussed are solely those of the author(s) and are not endorsed by BMJ. BMJ disclaims all liability and responsibility arising from any reliance placed on the content. Where the content includes any translated material, BMJ does not warrant the accuracy and reliability of the translations (including but not limited to local regulations, clinical guidelines, terminology, drug names and drug dosages), and is not responsible for any error and/or omissions arising from translation and adaptation or otherwise.

Open access This is an open access article distributed in accordance with the Creative Commons Attribution Non Commercial (CC BY-NC 4.0) license, which permits others to distribute, remix, adapt, build upon this work non-commercially, and license their derivative works on different terms, provided the original work is properly cited, appropriate credit is given, any changes made indicated, and the use is non-commercial. See: http://creativecommons.org/licenses/by-nc/4.0/.

\section{ORCID iD}

Giorgio Di Gessa http://orcid.org/0000-0001-6154-1845

\section{REFERENCES}

1 Huang C, Wang Y, Li X, et al. Clinical features of patients infected with 2019 novel coronavirus in Wuhan, China. The Lancet 2020;395:497-506.

2 Chen N, Zhou M, Dong X, et al. Epidemiological and clinical characteristics of 99 cases of 2019 novel coronavirus pneumonia in Wuhan, China: a descriptive study. Lancet 2020;395:507-13.

3 Jordan RE, Adab P. Who is most likely to be infected with SARS-CoV-2? Lancet Infect Dis 2020;20:995-6.

4 Guan W-J, Liang W-H, Zhao Y, et al. Comorbidity and its impact on 1590 patients with COVID-19 in China: a nationwide analysis. Eur Respir J 2020;55:2000547.

5 laccarino G, Grassi G, Borghi C, et al. Age and multimorbidity predict death among COVID-19 patients: results of the SARS-RAS study of the Italian Society of hypertension. Hypertension 2020;76:366-72.

6 Williamson EJ, Walker AJ, Bhaskaran K, et al. Factors associated with COVID-19related death using OpenSAFELY. Nature 2020:584:430-6.

7 Clark A, Jit M, Warren-Gash C, et al. Global, regional, and national estimates of the population at increased risk of severe COVID-19 due to underlying health conditions in 2020: a modelling study. Lancet Glob Health 2020;8:e1003-17.

8 Carroll WD, Strenger V, Eber E, et al. European and United Kingdom COVID-19 pandemic experience: the same but different. Paediatr Respir Rev 2020;35:50-6.

9 Cabinet Office. Guidance on social distancing for everyone in the UK, 2020. Available: https://web.archive.org/web/20200330181117/https://www.gov.uk/government/ publications/covid-19-guidance-on-social-distancing-and-for-vulnerable-people/ guidance-on-social-distancing-for-everyone-in-the-uk-and-protecting-older-peopleand-vulnerable-adults

10 Cabinet Office. Staying alert and safe (social distancing) after 4th July 2020. Available: https://web.archive.org/web/20200627051910/https:/www.gov.uk/government/ publications/staying-alert-and-safe-social-distancing/staying-alert-and-safe-socialdistancing-after-4-july

11 Cabinet Office. Guidance - Staying alert and safe (social distancing), 2020. Available: https://web.archive.org/web/20200603005323/https:/www.gov.uk/government/ publications/staying-alert-and-safe-social-distancing/staying-alert-and-safe-socialdistancing\#clinically-vulnerable-people

12 Pierce M, Hope H, Ford T, et al. Mental health before and during the COVID-19 pandemic: a longitudinal probability sample survey of the UK population. Lancet Psychiatry 2020;7:883-92.
13 McGinty EE, Presskreischer R, Han $\mathrm{H}$, et al. Psychological distress and loneliness reported by US adults in 2018 and April 2020. JAMA 2020;324:93-4.

14 Niedzwiedz CL, Green MJ, Benzeval M, et al. Mental health and health behaviours before and during the initial phase of the COVID-19 lockdown: longitudinal analyses of the UK household longitudinal study. J Epidemiol Community Health 2021;75:224-31.

15 Ettman CK, Abdalla SM, Cohen GH, et al. Prevalence of depression symptoms in US adults before and during the COVID-19 pandemic. JAMA Netw Open 2020;3:e2019686.

16 Bann Det al. Changes in the behavioural determinants of health during the coronavirus (COVID-19) pandemic: gender, socioeconomic and ethnic inequalities in 5 British cohort studies. medRxiv 2020.

17 Daly M, Sutin AR, Robinson E. Longitudinal changes in mental health and the COVID-19 pandemic: evidence from the UK household longitudinal study. Psychol Med 2020:1-10.

18 Vahia IV, Jeste DV, Reynolds CF. Older adults and the mental health effects of COVID-19. JAMA 2020:324:2253.

19 Steptoe A, Steel N. The experience of older people instructed to shield or self-isolate during the COVID-19 pandemic in ELSA COVID-19 Sub-study - Rapid Reports. London, 2020

20 Zaninotto P, Di Gessa G, Steel N. The experience of older people with multimorbidity during the COVID-19 pandemic, in ELSA COVID-19 Sub-study - Rapid Reports. London, 2020.

21 Fortin M, Lapointe L, Hudon C, et al. Multimorbidity and quality of life in primary care: a systematic review. Health Qual Life Outcomes 2004;2:51

22 Salisbury C, Johnson L, Purdy S, et al. Epidemiology and impact of multimorbidity in primary care: a retrospective cohort study. Br I Gen Pract 2011;61:e12-21.

23 Read JR, Sharpe L, Modini M, et al. Multimorbidity and depression: a systematic review and meta-analysis. J Affect Disord 2017;221:36-46.

24 Stickley A, Koyanagi A. Physical multimorbidity and loneliness: a population-based study. PLoS One 2018;13:e0191651.

25 Idler EL, Benyamini Y, Health S-R. Self-Rated health and mortality: a review of twentyseven community studies. J Health Soc Behav 1997;38:21-37.

26 Luo Y, Hawkley LC, Waite L, et al. Loneliness, health, and mortality in old age: a national longitudinal study. Soc Sci Med 2012:74:907-14.

27 Lee I-M, Shiroma EJ, Lobelo F, et al. Effect of physical inactivity on major noncommunicable diseases worldwide: an analysis of burden of disease and life expectancy. Lancet 2012;380:219-29.

28 He S, Craig BA, Xu H, et al. Unmet need for ADL assistance is associated with mortality among older adults with mild disability. J Gerontol A Biol Sci Med Sci 2015;70:1128-32.

29 Penninx BW, van Tilburg T, Kriegsman DM, et al. Effects of social support and personal coping resources on mortality in older age: the longitudinal aging study Amsterdam. Am J Epidemiol 1997:146:510-9.

30 Harris AHS, Thoresen CE. Volunteering is associated with delayed mortality in older people: analysis of the longitudinal study of aging. J Health Psychol 2005;10:739-52.

31 Banks Jet al. English longitudinal study of ageing: waves 0-9, 1998-2019. UK Data Service, 2019.

32 Beekman AT, Deeg DJ, Van Limbeek J, et al. Criterion validity of the center for epidemiologic studies depression scale (CES-D): results from a community-based sample of older subjects in the Netherlands. Psychol Med 1997;27:231-5.

33 Spitzer RL, Kroenke K, Williams JBW, et al. A brief measure for assessing generalized anxiety disorder: the GAD-7. Arch Intern Med 2006;166:1092-7.

34 Hyde $M$, Wiggins RD, Higgs $P$, et al. A measure of quality of life in early old age: the theory, development and properties of a needs satisfaction model (CASP-19). Aging Ment Health 2003; 7:186-94

35 Office for National Statistics. Measuring national well-being: measuring what matters, 2011. Available: http://www.statistics.gov.uk/articles/nojournal/ns-report-eng.pdf

36 Hughes ME, Waite LJ, Hawkley LC, et al. A short scale for measuring loneliness in large surveys: results from two population-based studies. Res Aging 2004;26:655-72.

37 Nazroo JY, Bhui KS, Rhodes J. Where next for understanding race/ethnic inequalities in severe mental illness? structural, interpersonal and institutional racism. Sociol Health IIIn 2020;42:262-76.

38 Bhala N, Curry G, Martineau AR, et al. Sharpening the global focus on ethnicity and race in the time of COVID-19. The Lancet 2020;395:1673-6.

39 Banks J, Karlsen S, Oldfield Z. Socio-Economic position, in health, wealth and lifestyles of the older population in England. London: Institute for Fiscal Studies, 2003: 71-125.

40 Steinman MA, Perry L, Perissinotto CM. Meeting the care needs of older adults isolated at home during the COVID-19 pandemic. JAMA Intern Med 2020:180:819-20. 